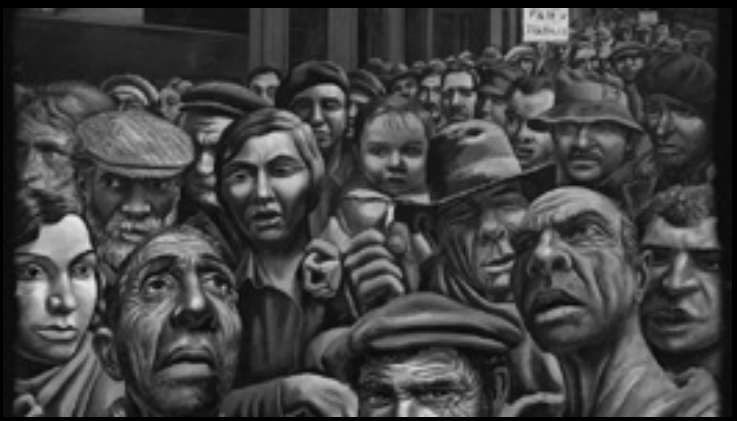

Berni, Antonio, Manifestación 1934 (Óleo sobre arpillera). Museo de Arte Latinoamericano de Buenos Aires MALBA. 


\section{Violencia política y guerra sucia en Colombia. Memoria de una víctima del conflicto colombiano a propósito de las negociaciones de la Habana Political Violence and Dirty War in Colombia. Remembrance of a Victim of the Colombian Conflict in Relation to the Havana Negotiations Violência política e guerra suja na Colômbia. Memória de uma vítima do conflito colombiano a propósito das negociações da Havana}

Jenner Alonso Tobar Torres

Universidad de Buenos Aires

(Buenos Aires, Argentina)

jatovart@unal.edu.co
Artículo de reflexión elaborado en el marco del curso de Historia del Derecho en el doctorado en derecho de la Universidad de Buenos Aires, elaborado entre los años 2012 y 2013.

\section{Resumen}

La violencia como herramienta política ha sido una constante en el conflicto interno colombiano desde hace más de 25 años, cuando el fenómeno paramilitar inició un vertiginoso ascenso que lo llevaría a cooptar gran parte de la institucionalidad a inicios del siglo xxi. El paramilitarismo, el narcotráfico y las guerrillas han generado cientos de miles de víctimas en Colombia, y hoy, cuando el Estado colombiano adelanta negociaciones de paz con el principal grupo guerrillero, los derechos de las víctimas crean una tensión entre quienes exigen su plena aplicación y entre quienes consideran que en escenarios de justicia transicional existen posibilidades de ponderación entre los derechos de las víctimas y la existencia de un marco legal que permita la finalización negociada del conflicto. En este contexto, se presenta el relato de Gloria Mancilla, víctima del conflicto, y sus demandas de verdad y justicia frente a las negociaciones de paz en desarrollo.

\section{Abstract}

Violence as a political tool has been a constant in the Colombian internal conflict for more than 25 years, when the paramilitary phenomenon began a dramatic rise that later led it to co-opt a considerable part of the institutions in the early twenty-first century. Paramilitarism, drug trafficking and guerrillas have generated hundreds of thousands of victims in Colombia. Nowadays, when the Colombian State advances the peace negotiations with the main guerrilla group, the victims' rights create tension between those who demand their full implementation and those who consider that in transitional justice contexts there are possibilities for balancing between the victims' rights and the existence of a legal framework that could enable negotiating the end to the conflict. In this context, the story of Gloria Mancilla, one of the victims of the conflict, is presented, as well as her demands for truth and justice in the ongoing peace negotiations.

\section{Palabras clave}

violencia política; paramilitarismo; derecho de las víctimas; proceso de paz Colombia

\section{Keywords}

political violence; paramilitarism; victims' rights; Colombian peace process

\section{Resumo}

A violência como ferramenta política tem sido uma constante no conflito interno colombiano há mais de 25 anos atrás, quando o fenómeno paramilitar iniciou um vertiginoso ascendimento que levaria ele cooptar boa parte da institucionalidade a inicios do século xxi. $\mathrm{O}$ paramilitarismo, o narcotráfico e as guerrilhas geraram centos de milhares de vítimas na Colômbia, e hoje, quando o Estado colombiano adianta negociações de paz com o principal grupo guerrilheiro, os direitos das vítimas criam tensão entre quem exige sua plena aplicação e quem considera que nos cenários de justiça transicional existem possibilidades de ponderação entre os direitos das vítimas e a existência de um marco legal que permita a finalização negociada do conflito. Nesse contexto, apresenta-se o relato de dona Gloria Mancilla, vítima do conflito e suas demandas de verdade e justiça frente às negociações de paz em desenvolvimento.

\section{Palavras-chave}

violência política; paramilitarismo; direito das vítimas; processo de paz na Colômbia 
Algunos ya no quieren recordar, otros han perdido la razón, otros viven en el silencio huyendo del terror, otros se han ido al exilio escapando de la muerte, otros sufren en silencio el dolor por los ausentes. Pero algunos cuentan sus historias, no se resignan al silencio.

Hablan para que la verdad se conozca y se haga justicia. Su voz es una alerta. Todos los colombianos, sin excepción, debemos escucharla si queremos un pais al fin reconciliado. Yesid Campos Zornoza ${ }^{1}$

\section{A modo de introducción: breve exposición del contexto histórico}

Colombia es un Estado atravesado por décadas de conflicto interno que ha llevado de un modo u otro a que los colombianos nos habituemos a que ocurran hechos violentos en nuestro país. No en vano en un informe denominado «Carga Global de la Violencia Armada 2011», publicado por la Secretaría de la Declaración de Ginebra sobre Violencia Armada y Desarrollo, Colombia ocupa la nada honrosa quinta posición en la lista de países con mayor promedio anual de muertes violentas en el mundo 2 .

La violencia ha sido elemento constante en nuestra historia, por ello hablar de esta en Colombia no es sencillo. En palabras del historiador Gonzalo Sánchez:

Para los detentadores del poder, a través de más de ciento cincuenta años de bipartidismo, Colombia es un paradigma de democracia y de civilismo en América latina. ¿Cómo ha podido sostener y defender esta imagen un país que después de catorce años de guerra de independencia, vivió durante el siglo XIX ocho guerras generales, catorce guerras civiles locales, dos guerras internacionales con Ecuador y tres golpes de cuartel?, como ha podido sostenerla, cuando en el siglo $\mathrm{xx}$, aparte de los numerosos levantamientos locales, libra una guerra con Perú, es escenario, en 1948, de una de las más grandes insurrecciones contemporáneas, seguida por la más larga de las guerras, precisamente a la que se denomina de manera específica como «violencia», ¿cómo, en fin, si se tiene en cuenta que en este país se está negociando con la que se considera la más vieja guerrilla Latinoamericana? ${ }^{3}$

1 El baile rojo. Relatos no contados del genocidio de la up (Bogotá: Debate, 2008).

2 Secretaría de la Declaración de Ginebra sobre Violencia Armada y Desarrollo, Carga Global de la Violencia Armada 2011. Encuentros letales. http://www.genevadeclaration.org/ measurability/global -burden-of-armed-violence/global-burden-of-armed-violence-2011.html (consultado el 11 de noviembre de 2013).

3 Gonzalo Sánchez, «Los estudios sobre la violencia: balance y perspectivas», en Pasado y presente de la violencia en Colombia,
En este sentido, la mayoría de estudios sobre violencia y conflicto colombiano han coincidido en señalar que en Colombia se debe hablar de «violencias", pues en distintos escenarios temporales y sociales diversas formas de conflicto han sacudido el territorio colombiano. Así, solamente en el siglo xx se puede mencionar la existencia de una violencia partidista (décadas de los veinte y de los cincuenta), de una violencia guerrillera (floreciente a partir de la década de los sesenta), de una violencia mafiosa impulsada por el negocio del narcotráfico (surgida a partir de la década de los ochenta), de una violencia política y paramilitar (desde la década de los ochenta y con pleno auge en los noventa), de una creciente violencia desorganizada (riñas, delincuencia común), entre otras ${ }^{4}$. Desde los años ochenta y hasta la actualidad son principalmente tres los fenómenos sociales generadores de violencia organizada que han irrumpido en la vida diaria de la sociedad colombiana: 1) los grupos guerrilleros, especialmente las FARC, el ELN, y el EPL; 2) el surgimiento y desarrollo de grupos paramilitares; 3) el auge del narcotráfico ${ }^{5}$. A estos tres fenómenos cabe agregar al Estado como actor activo dentro del conflicto, de cuyas dinámicas y tensiones respecto a los demás actores se deriva la violencia de Estado como fenómeno plenamente identificable, tal como se expondrá. La conjunción de estos fenómenos de violencia, principalmente a partir de los años ochenta, dio origen a una de las más oscuras épocas de la historia colombiana en la que el ejercicio reiterado y parainstitucionalizado de la violencia como elemento político en Colombia se convirtió en una constante.

Una de las décadas más convulsionadas de la historia colombiana fue la de los ochenta. Al iniciar esta el país parecía estar superando una larga etapa de violencia partidista pero se sumergía en una cada vez más extendida violencia guerrillera.

comp. Gonzalo Sánchez y Ricardo Peñaranda (Medellín: La Carreta Editores, 2007), 17.

4 Carlos Alberto Patiño Villa, Guerra y construcción del Estado en Colombia 1810-2010 (Bogotá: Universidad Militar Nueva Granada, 2010), 200-201; Daniel Pecaut, Guerra contra la sociedad (Bogotá: Espasa, 2001), 90 y ss.

5 Ricardo Peñaranda, «La guerra en el papel. Balance de la producción sobre la violencia durante los años noventa», en Pasado y presente de la violencia en Colombia, ed. Gonzalo Sánchez y Ricardo Peñaranda (Medellín: La Carreta Editores, 2007), 39. 
Desde 1958 y hasta 1974 los partidos políticos tradicionales (liberal y conservador) realizaron una coalición política mediante la cual decidieron alternarse el ejercicio del poder durante cuatro periodos presidenciales (16 años) con el propósito de reorganizar el país luego del gobierno dictatorial de Gustavo Rojas Pinilla y superar definitivamente la violencia partidista generada desde 1946 con el asesinato de Jorge Eliecer Gaitán. Durante el periodo del Frente Nacional existieron elecciones presidenciales, pero a la contienda electoral solamente se presentaron candidatos del partido político a quien le correspondía el turno de gobernar.

Si bien con este pacto político la violencia partidista parecía superarse, se generó una lucha de resistencia armada contra un sistema político cerrado y excluyente en el cual no existía real ejercicio de una oposición política y social. Esto llevó al Estado a crear un conjunto de normativas que, con pretexto de la protección a la seguridad interna, limitaba y criminalizaba el ejercicio de la oposición y aumentaba las facultades militares y de policía (vgr., Decreto 1705 de 1960, Decreto 3398 de 1965, Decreto 1357 de 1964', etc.).

Una vez terminado el periodo del Frente Nacional, la autonomía militar había llegado a su punto más alto, lo cual, sumado al mayor terreno que diariamente ganaban las guerrillas en su lucha armada y a la profunda ideologización y politización anticomunista de las Fuerzas Armadas Colombianas, hicieron que estas ejercieran presión sobre el gobierno para implementar medidas más drásticas de protección de la seguridad nacional. Esto se materializó mediante el uso común de la figura del Estado de Sitio o de Excepción y con el conocido Estatuto de Seguridad de 1978. Dicho estatuto limitó las garantías procesales de defensa en el caso de detención, allanamiento de muebles y garantía del debido proceso especialmente en relación con las sentencias que dictaban los comandantes de las fuerzas armadas, que

6 Presidencia de la República de Colombia, Decreto 1705 del 11 de agosto de 1960. Por el cual se reorganiza el Ministerio de Guerra y se determinan sus funciones; Presidencia de la República de Colombia, Decreto 3398 del 25 de enero de 1965. Por el cual se organiza la defensa nacional; Presidencia de la República de Colombia, Decreto 1357 del 10 de junio de 1964. Por el cual se dictan disposiciones sobre el levantamiento de los censos nacionales de Población, Edificios, Viviendas y Ganadero. en la atribución de nuevas competencias les permitió juzgar delitos de tipo político como manifestaciones, huelgas, paros cívicos y otro tipo de acciones colectivas. Asimismo, consagraba el delito de perturbación del orden público y censuraba a los medios de comunicación al impedir transmitir por radio y televisión informaciones o declaraciones relativas al orden público, lo cual atentó contra el derecho a estar informado y permitió ahondar en un clima de autocensura ${ }^{7}$.

Colombia atravesaba una difícil polarización del miedo: por una parte el miedo al actuar de las guerrillas que cada vez ganaban mayor control militar y territorial en su lucha armada, y, por otra parte, el miedo a la represión estatal, pues los casos de detenciones arbitrarias, desapariciones forzadas y torturas a manos de la fuerza pública comenzaban a ser cada vez mayores, justificándose dicho accionar en la defensa de la seguridad interna, en una política del enemigo. Dentro de este clima de tensión, en 1982 obtendría la presidencia Belisario Betancur, quien buscando crear un escenario de diálogo con los principales actores del conflicto armado (las guerrillas de las FArc y el M-19) suspendió el Estatuto de Seguridad y otorgó una ley de amnistía incondicional a presos políticos. Este fue el inicio de un proceso de paz con las guerrillas, que en el caso de las FARC tuvo su clímax el 28 de marzo de 1984 con el acuerdo de «Cese al fuego, tregua y paz».

Este acuerdo fue el origen del Movimiento Político Unión Patriótica (UP), el cual nació como resultado de una propuesta de construir un frente amplio de convergencia democrática en el que participarían diversos grupos políticos y sociales. Como señala Campos, allí tendrían cabida:

\footnotetext{
Insurgentes, comunistas, socialistas, liberales, conservadores, grupos religiosos, ecologistas, independientes, gente del arte y la cultura, y todos aquellos interesados en el objetivo de luchar por reformas políticas, económicas y sociales que garanticen una paz democrática. La propuesta fue parte de una estrategia para alcanzar y consolidar una salida política negociada al conflicto armado, que permitiese que, una vez logrado el acuerdo
}

\footnotetext{
7 Catalina Turbay Jiménez, «El Estatuto de Seguridad: un estudio de caso», en 1er. Congreso de ciencia política, 30 de septiembre al 4 de octubre de 2008. http://congresocienciapolitica.uniandes.edu. $\mathrm{co} /$ (consultado el 7 de noviembre de 2013).
} 
de paz, las Farc dejaran las armas y se vincularan de lleno a la vida civil y a la actividad política y legal ${ }^{8}$.

La up surge en 1985 como un nuevo movimiento político amplio, pluralista e inclusivo en el que convergen diversas fuerzas políticas, principalmente de izquierda, tales como el Movimiento de Autodefensa Obrera (ADO), Movimientos Firmes, Juventud Comunista, Partido Comunista Colombiano, Partido Socialista Revolucionario, Frente Democrático, sectores del Nuevo Liberalismo, sectores del Liberalismo Independiente Unidad Liberal Popular, Movimiento de Convergencia Liberal, Nueva Fuerza Liberal, sectores del Conservatismo y diversas organizaciones de carácter cívico, obrero y popular'.

Tal fue el interés y acogida que generó este movimiento político que en su primera experiencia electoral en marzo de 1986 son elegidos 14 congresistas para Cámara y Senado, 18 diputados para 11 asambleas departamentales, 355 concejales para 187 Consejos, y en mayo del mismo año su candidato presidencial, el ex magistrado y sindicalista Jaime Pardo Leal, obtiene cerca de 320 mil votos, convirtiéndose la up en la tercera fuerza electoral más importante del país.

Parecía que el país entraba en un proceso de apertura democrática que consolidaría la posibilidad de los ciudadanos de proponer un verdadero proceso de transformación de las estructuras políticas y sociales de desigualdad, y que permitiría a los grupos guerrilleros su reinserción a la vida civil y política. Sin embargo, esto estaba muy lejos de convertirse en realidad.

\section{El caso de la Unión Patriótica: la «guerra sucia» y el exterminio sistemático de la política de izquierda en Colombia}

Al tiempo que el Estatuto de Seguridad y los Estados de Excepción eran la herramienta del Gobierno nacional para garantizar la seguridad interna del Estado, surgían en el país las llamadas Autodefensas Campesinas, embrión de lo

8 Campos Zornosa, El baile rojo, 23.

9 Iván David Ortiz Palacios, Genocidio político contra la Unión Patriótica: nuevas miradas para nuevas lecturas (Bogotá: Universidad Nacional de Colombia, 2006), 60. que posteriormente se conocería como paramilitarismo. Con fundamento normativo en decretos nacionales y auspiciado por los militares, en zonas rurales del país se comenzaron a crear grupos de autodefensas que tenían como objetivo principal resistir por sí mismas las presiones de las guerrillas y, en algunos casos, vengar los crímenes perpetuados por estas ${ }^{10}$.

La zona de Puerto Boyacá y el Magdalena medio fue uno de los primeros laboratorios de paramilitarismo, justamente donde el Partido Comunista y las fuerzas políticas de izquierda habían consolidado un importante apoyo electoral. En 1986, en aparente respuesta a los raptos y extorsiones que la guerrilla efectuaba sobre los ganaderos de la zona, se crea Acdegam (Asociación de Campesinos y Ganaderos del Magdalena medio), financiada por cotizaciones pagadas por los ganaderos y con funciones de vigilancia militar y de ayuda social. Experiencias de este tipo se repitieron en varias zonas del país, prácticamente en cualquier lugar en el que existiera producción de riqueza que atrajera a poblaciones migrantes $y$, en consecuencia, fuera un escenario estratégico para los protagonistas armados ${ }^{11}$.

Rápidamente se comenzó a distinguir entre los primigenios grupos de autodefensas y la aparición de grupos paramilitares encargados de operaciones ofensivas y compuestos de miembros remunerados, en los cuales los narcotraficantes vieron la oportunidad perfecta para construir sus propios cuerpos armados que respondieran a sus intereses económicos y políticos. Mientras el gobierno endurecía su posición frente a los narcotraficantes y la posibilidad de extradición, estos encontraban en el paramilitarismo la forma de reforzar sus vínculos no solo con los grandes propietarios y compañías, sino con las Fuerzas Armadas. En efecto, ante el temor del avance de la guerrilla amparada por el cese al fuego decretado en 1985 y el aumento de la violencia en varias zonas del país, las Fuerzas Armadas se lanzaron discretamente a lo que se conoció como "guerra sucia» ${ }^{12}$.

10 Luis Fernando Barón Porras, Historias no oficiales de guerra y paz (Bogotá: cinep, 2006), 80.

11 Daniel Pecaut, Crónica de cuatro décadas de política colombiana (Bogotá: Grupo Editorial Norma, 2006), 393 y ss.

12 Pecaut, Guerra contra la sociedad, 176. 
En la medida en que los paramilitares son actores prosistémicos, es decir sus acciones ilegales no están destinadas a combatir el status quo sino a mantenerlo, durante muchos años estos grupos fueron tolerados, cuando no apoyados, por el Estado. El ejército se benefició muchas veces de su actividad subversiva y muchos de sus agentes establecieron estrechos lazos de complicidad y colaboración con los paramilitares ${ }^{13}$.

Surgió entonces una siniestra alianza entre grandes propietarios, militares y narcotraficantes para conformar grupos paramilitares, los cuales, pese a su fundamentación,

[...] raramente se orientaban hacia las guerrillas como tales; buscaban más bien destruir aliados politicos y simpatizantes de las guerrillas. Dirigentes y miembros de la uP fueron su primer objetivo: de mil quinientos a dos mil militantes fueron asesinados en poco tiempo; los sindicalistas y los cuadros de las organizaciones campesinas no dejaron de ser considerados como objetivo $^{14}$ (cursiva propia).

Este modus operandi de los actores paramilitares mantiene vigencia en la actualidad. Recientes investigaciones muestran que el paramilitarismo colombiano no se ha desarrollado como un actor contrainsurgente, pues las zonas donde operan las estructuras paramilitares no se han caracterizado por un combate frontal a las guerrillas. Además, se ha establecido que en los casos en los que existieron enfrentamientos entre estructuras paramilitares y guerrilleras generalmente la iniciativa la han tenido las guerrillas. En este sentido, se puede afirmar que la acción armada de la guerrilla ha sido antiparamilitar, pero la del paramilitarismo ha sido mínimamente contrainsurgente ${ }^{15}$.

Pese a su marcado carácter pluralista y participativo de distintas tendencias de izquierda, la UP fue estigmatizada por los grupos paramilitares $y$ por miembros del propio Estado como «el brazo

13 Mauricio García Villegas; Javier Revelo Rebolledo y Rodrigo Uprimny Yepes, «Impacto constitucional e institucional de la Ley de Justicia y Paz», en Y refundaron la patria... De cómo mafiosos y políticos reconfiguraron el Estado Colombiano, ed. Claudia López (Bogotá: Debate, 2010), 329.

14 García Villegas; Revelo Rebolledo y Uprimny Yepes, «Impacto constitucional», 176-177.

15 Ariel Fernando Ávila Martínez, «Injerencia política de los grupos armados ilegales», en Y refundaron la patria... De cómo mafiosos y políticos reconfiguraron el Estado Colombiano, ed. Claudia López (Bogotá: Debate, 2010), 79. político de las FARC» ${ }^{16}$. Lo anterior, sumado a la guerra que por el control del negocio de la coca declaró el poderoso narcotraficante Gonzalo Rodríguez Gacha a las FARC ${ }^{17}$, convirtió a los militantes de la up y de izquierda en objetivos militares.

Lo que sigue se puede resumir en una palabra: exterminio. Mediante el homicidio y la desaparición forzada, miembros de la up, del Partido Comunista y dirigentes campesinos y gremiales fueron exterminados sistemáticamente en acciones que, en muchos casos, comprometieron a miembros de la fuerza pública y que respondieron a planes de ejecución sistematizados. Estos incluían desplazamientos forzados, desapariciones, homicidios, torturas y atentados fallidos contra sus militantes, como el llamado Plan Baile Rojo, Plan Condor, Plan Esmeralda y Plan Retorno, entre otros, que en cierta medida lograron su objetivo: acallar las voces de miles de colombianos que eran dignos opositores políticos del gobierno ${ }^{18}$.

Además de sus bases de militantes, gobernantes y políticos locales, el plan de exterminio fue tan evidente que continuamente, uno tras otro, a los ojos de un país impávido, los dirigentes de la UP fueron asesinados. Según cifras oficiales de la Presidencia de la Republica, fueron asesinados 302 dirigentes de la $\mathrm{UP}^{19}$, aunque esta cifra dista mucho de la presentada por la UP ante la Comisión Interamericana de Derechos Humanos en la que se habla de 1.163 ejecuciones extrajudiciales, tal como se señala más adelante.

Uno de los homicidios que más conmovió al país fue el del abogado, ex magistrado, sindicalista y dirigente de la UP Jaime Pardo Leal, asesinado el 11 de octubre de 1987 al parecer por órdenes del narcotraficante Gonzalo Rodríguez Gacha $^{20}$. La intensidad de esta "guerra sucia» llevó a las FARC a romper los diálogos de paz a finales de 1987 y a desvincularse de la up, descartando la vía de desmovilización y de la acción políti-

16 Ortiz Palacios, Genocidio político, 60.

17 Pecaut, Crónica de cuatro décadas, 393 y ss.

18 Iván David Ortiz Palacios, Jaime Pardo Leal, Patriota de la Unidad (Bogotá: Universidad Nacional de Colombia, 2008), 156.

19 Diego Otero Prada, Las cifras del conflicto colombiano (Bucaramanga: Uniciencia, 2007), 174.

20 «Condena a nación por asesinato de Pardo Leal», El Tiempo [Bogotá], 1 de noviembre, 1997. http://www.eltiempo.com/archivo/ documento/MAM-698810 (consultado el 16 de octubre de 2013). 
ca. Sin embargo, esto no influiría en nada el desarrollo del plan de exterminio. El 27 de febrero de 1989 fue asesinado Teófilo Forero, dirigente del partido Comunista Colombiano y días más tarde, el 3 de marzo de 1989, sería muerto José Antequera, dirigente nacional de la up y secretario nacional del Partido Comunista. Bernardo Jaramillo Ossa, senador de la up, presidente del partido tras el asesinato de Jaime Pardo Leal y candidato presidencial al momento de ser asesinado, fue muerto el 22 de marzo de 1990; hasta el momento la justicia no ha esclarecido los autores intelectuales del crimen, aunque se apunta a que el homicidio fue ordenado por el jefe paramilitar Fidel Castaño con participación de agentes del Estado ${ }^{21}$.

Vale decir que días después, el 26 de abril, Carlos Pizarro, candidato presidencial por el M-19, también fue asesinado y 7 meses antes, el 18 de agosto de 1989, había sido acribillado el candidato del partido liberal Luis Carlos Galán, férreo enemigo del narcotráfico y con alta opción de ganar las elecciones. Para las elecciones presidenciales de 1990 en total tres candidatos presidenciales fueron asesinados.

Manuel Cepeda Vargas, carismático dirigente de la UP, fue asesinado el 9 de agosto de 1994 y por su crimen el Estado colombiano fue condenado por la Corte Interamericana de Derechos Humanos ${ }^{22}$.

En 1993 la up decidió presentar este exterminio sistemático ante la Comisión Interamericana de Derechos Humanos (CIDH) exponiendo una lista de 1.163 miembros de la up que fueron ejecutados extrajudicialmente entre 1985 y 1993, 123 personas que fueron desaparecidas por la fuerza, 43 personas que sobrevivieron atentados de asesinato y 225 personas que recibieron amenazas durante el mismo periodo. Se configuró así una práctica de asesinatos políticos en masa y la persecución extrema de los miembros de la UP con

21 Redacción Judicial, «Revive el caso de Bernardo Jaramillo», El Espectador [Bogotá], 21 de noviembre, 2009. http://www.elespectador.com/impreso/judicial/articuloimpreso173433-revive-el-caso-de-bernardo-jaramillo (consultado el 17 de octubre de 2013).

22 Corte Interamericana de Derechos Humanos, Caso Manuel Cepeda Vargas Vs. Colombia. Excepciones Preliminares, Fondo, Reparaciones y Costas. Sentencia de 26 de mayo de 2010. Serie C No. 213. http://www.corteidh.or.cr/docs/casos/articulos/seriec_213_esp.pdf (consultado el 27 de agosto de 2013). la intención de eliminar físicamente al partido y de diluir su fuerza política.

La CIDH admitió el caso en 1997 estableciendo que los hechos expuestos por los demandantes contienen elementos similares a los del genocidio, por lo cual

[...] se podría entender que sí lo constituyen, interpretando este término de conformidad con su uso corriente. Sin embargo, la Comisión ha llegado a la conclusión de que los hechos alegados por los peticionarios no caracterizan, como cuestión de derecho, que este caso se ajuste a la definición jurídica actual del delito de genocidio consignada en el derecho internacional ${ }^{23}$.

Luego de fracasar la posibilidad de una solución amistosa entre el Estado colombiano y los demandantes, en junio de 2006 el caso pasó a conocimiento de la Corte Interamericana de Derechos Humanos, en donde se encuentra pendiente de solución.

\section{El hoy por hoy de la «guerra sucia»}

El uso de la violencia con fines políticos y electorales ha sido una constante en Colombia en los últimos 25 años, y es claro que principalmente fueron los grupos paramilitares, asociados con la mafia del narcotráfico, quienes impusieron por medio de la violencia un proyecto político que hoy en día no se termina de develar. Según cifras del Comité Permanente por la Defensa de los Derechos Humanos (CPDH), entre 1966 y 2003 la cifra de homicidios políticos en Colombia fue de $44.133^{24}$.

Incluso en la actualidad se puede señalar que los eventos de violencia política no han cesado:

De acuerdo con datos de Reiniciar y de la Comisión Colombiana de Juristas, entre 2002 y 2007 se han perpetrado alrededor de 136 homicidios, 38 casos de desaparición forzada y 28 intentos de homicidio de personas vinculadas a este movimiento político. Así se ha consolidado el aniquilamiento sistemático y organizado contra un grupo político legal en un Estado democrático y constitucional. A nivel internacional esto constituye un hecho singular, pues ha tenido lugar no bajo un régimen dictatorial sino en un país de institu-

\footnotetext{
23 Comisión Interamericana de Derechos Humanos, Informe no 5/97, caso 11.227, sobre admisibilidad, Colombia, 12 de marzo de 1997. http://www.cidh.org/annualrep/96span/colombia11227.htm (consultado el 27 de agosto de 2013).

24 Otero Prada, Las cifras, 174.
} 
ciones democráticas, en donde el Estado y los gobiernos no hicieron lo que les corresponde para impedirlo ${ }^{25}$.

Así pues, para Colombia no se puede hablar de la permanencia de una democracia consolidada sino de la presencia de formas democráticas que han sido manipuladas al antojo e intereses de los actores de poder. De hecho, las mismas estructuras paramilitares y mafiosas responsables del exterminio de las fuerzas políticas de izquierda durante las últimas décadas del siglo xx son las que en la primera década del siglo xxi lograron cooptar buena parte de la política e institucionalidad en Colombia mediante su penetración violenta e ilegítima, en el ámbito tanto local como nacional.

Narcotráfico y paramilitarismo penetraron lenta y exitosamente en la política colombiana: en 1994, con el llamado «Proceso 8000», se demostró que el Cartel de Cali entró mediante financiamiento de campañas al Congreso de la Republica y a la presidencia de Ernesto Samper. En 2002:

[...] los congresistas electos con el apoyo del narco paramilitarismo obtuvieron el 34\% de las curules y más de dos millones de votos, equivalentes al $25 \%$ de la votación en Senado. Ocho de cada diez de esos congresistas entraron a hacer parte de la coalición del presidente Uribe y cogobernaron con él desde entonces. En 2006 casi todos los congresistas de la parapolítica fueron reelegidos y mantuvieron la misma proporción y representatividad dentro de la colación de gobierno ${ }^{26}$.

A partir de 2006, cuando surgió a la luz pública los primeros indicios del andamiaje mafioso y paramilitar que había penetrado la institucionalidad colombiana, las cifras no han parado de aumentar. A abril de 2010 la Fiscalía se encontraba investigando por vínculos con el paramilitarismo a 324 miembros de la fuerza pública, 109 servidores públicos, 400 políticos de elección popular, entre los cuales 102 son congresistas y 25 de ellos ya se encuentran condenados ${ }^{27}$.

La cooptación del Estado a manos de estructuras de poder organizado con componentes armados, financieros, mafiosos y políticos es un

25 Claudia López Hernández, «La refundación de la patria, de la teoría a la evidencia», en Y refundaron la patria... De cómo mafiosos y políticos reconfiguraron el Estado Colombiano, ed. Claudia López (Bogotá: Debate, 2010), 33.

26 López Hernández, «La refundación», 33.

27 López Hernández, «La refundación», 29-31. proceso que le ha costado al país miles de víctimas. Según datos aportados en la investigación de Claudia López, en abril de 2010 la Unidad de Justicia y Paz de la Fiscalía General de la Nación oficializó que a partir de las denuncias hechas por víctimas, las indagaciones de fiscales y las confesiones de los desmovilizados, se han logrado establecer las siguientes cifras de violencia asociada al conflicto, en las que se estima que al menos el $98 \%$ fueron cometidas por grupos narcoparamilitares (ver tabla 1 ).

Tabla 1. Hechos de violencia asociados al conflicto armado

\begin{tabular}{|l|l|}
\hline Conducta / Hechos de violencia & $\begin{array}{l}\text { Número de casos } \\
\text { documentados }\end{array}$ \\
\hline Homicidios & 163.762 \\
\hline Desaparición forzada & 31.841 \\
\hline Masacres & 1.309 \\
\hline $\begin{array}{l}\text { Reclutamiento de menores (menores } \\
\text { identificados y ubicados como } \\
\text { víctimas de reclutamiento) }\end{array}$ & 3.557 \\
\hline $\begin{array}{l}\text { Desplazamiento forzado masivo (por } \\
\text { comunidades) }\end{array}$ & 66.562 \\
\hline Violencia de género & 552 \\
\hline Secuestros & 2.860 \\
\hline Extorsión & 3.184 \\
\hline Narcotráfico & 58 \\
\hline Otras conductas & 25.718 \\
\hline $\begin{array}{l}\text { Participación de la fuerza pública } \\
\text { con grupos armados ilegales (citados } \\
\text { por postulados en versión libre bajo } \\
\text { juramento) }\end{array}$ & 328 \\
\hline
\end{tabular}

Fuente: López Hernández, $2010^{28}$

Las cifras resultan escalofriantes por sí solas.163.762 es el número de homicidios que se han denunciado en los últimos 25 años. Considerando únicamente los 31.841 casos de desaparición forzada, esta cifra es tres veces mayor a los casos documentados de desaparición en las tres dictaduras del cono sur sumadas. Este ha sido el costo de la consolidación política de la mafia y el paramilitarismo.

El exterminio de la up, con sus cerca de 6.000 muertos y desaparecidos, fue el inicio del macabro camino que las estructuras mafiosas adelantaron para consolidar su poder militar, económico y político con la aquiescencia del Estado: «no solo asesinaron seres humanos, masacraron un proyecto de país diferente en el que los colombianos

28 López Hernández, «La refundación», 76. 
tenían puestas sus esperanzas» ${ }^{29}$. En adelante la sociedad colombiana tendría que asistir a una sangrienta consolidación del poder mafioso en el territorio colombiano, junto con el incesante actuar delictivo de las guerrillas.

Cada uno de los 163.762 homicidios o de las 31.842 desapariciones, más que una cifra del conflicto, son vidas silenciadas que dejan compañeros, $\mathrm{pa}^{-}$ dres, hijos, amigos, vecinos y una sociedad que merecen y necesitan saber la verdad de lo sucedido. La verdad es el primer paso para la reconciliación de la sociedad, y ante las apabullantes cifras del conflicto es poco probable que mediante la vía judicial se llegue a la resolución de cada uno de estos casos.

En un conflicto tan extendido en el tiempo y de proporciones tan amplias en cuanto a crímenes y víctimas, cualquier aparato estatal de justicia resultaría insuficiente para investigar y juzgar cada uno de los crímenes cometidos. En el caso colombiano, a 2010 se habían denunciado alrededor de 380.000 hechos delictivos relacionados con el conflicto armado; si se pretendiera investigar caso a caso, esta labor tardaría más de 100 años.

\section{La lucha de las víctimas: una lucha por la memoria, contra la impunidad. El caso de Gloria Mancilla ${ }^{30}$}

E1 5 de septiembre de 1984 fue la última vez que Gloria Mancilla vio a su esposo Miguel Ángel Díaz, cuando él salió de su casa con rumbo al municipio de Puerto Boyacá con el fin de recuperar una vieja casa que había servido de sede del Partido Comunista, donde militaba, y que había sido abandonada desde la expulsión violenta de su militancia. Ese día en el municipio de Puerto Boyacá, a las 11:30 am, Miguel Ángel fue introducido a la fuerza en un carro Renault 12, al que seguía una motocicleta roja conducida por el

29 Ortiz Palacios, Jaime Pardo Leal, 155.

30 Este relato se construye con base en lo narrado por Gloria Mancilla en entrevista con el autor. Asimismo, se utilizó el relato contenido en Campos Zornosa, El baile rojo, 157 y ss., así como en las noticias de prensa de Carlos A. Lozano Guillen, «Familiares en pie de lucha», en Periódico Voz [Bogotá], 14 de septiembre 14, 2011, 3, y Natalia Herrera Durán, «La lucha de la familia Díaz Mancilla», en El Espectador [Bogotá], 5 de septiembre, 2011. http://www. elespectador.com/noticias/judicial/lucha-de-familia-diaz-mancilla-articulo-297185 (consultado el 17 de noviembre de 2013). detective rural del Departamento Administrativo de Seguridad (DAS) Jorge Luis Barrero, y desde entonces nadie dio razón de su paradero.

Miguel Ángel era militante del Partido Comunista y dirigente sindical de la Federación Nacional de Trabajadores al Servicio del Estado (Fenaltrase), pero además era esposo de Gloria Mansilla y padre de tres hijas, quienes al momento de su desaparición tenían 9 años, 8 años y 20 meses, respectivamente.

La época de su desaparición coincidió con el momento en que, en el marco del proceso de paz que el gobierno de Belisario Betancour adelantaba con las FARC, se realizaban los programas y preparativos para el nacimiento de la up. Miguel Ángel se vinculó en esta labor, por lo cual su esposa afirma que «eso es lo único que uno puede pensar como motivo de su desaparición. Sin embargo, insisto en que nada justifica ese método monstruoso y terrible que han ejecutado para acabar con dirigentes populares y sociales» ${ }^{31}$.

La desaparición de Miguel Ángel fue denunciada ante las autoridades y luego de un proceso penal fue condenado a 5 años de prisión el agente rural del DAs, Jorge Luis Barrero, por el cargo de secuestro simple de dos personas, de los cuales solamente cumplió tres porque salió por buena conducta. Los responsables intelectuales no han sido procesados pese a evidencias que apuntan a su identificación.

La verdad de lo acontecido con Miguel Ángel, así como su paradero final, nunca se ha conocido. Esta es la lucha actual de doña Gloria Mancilla y sus hijas, la verdad y la justicia, y así lo indica en sus palabras:

La verdad está en saber quiénes fueron realmente los autores intelectuales, en saber dónde está Miguel Ángel y en encontrarlo, y la justicia está en el castigo a los responsables. [...] La desaparición forzada es un sistema de tortura permanente. A pesar de la persistencia diaria en saber la verdad, uno siente miedo cuando tiene una opción seria de saberla, siente miedo enfrentarla. [...] Creo que ese es uno de los retos más difíciles que tenemos los familiares de desaparecidos: luchar por conservar nuestra capacidad de búsqueda de la verdad ${ }^{32}$.

\footnotetext{
31 Gloria Mancilla, entrevistada por el autor, Madrid, 21 de enero, 2012. 32 Mancilla, entrevistada por el autor.
} 
No obstante, además de tener que soportar el dolor y la ausencia de su ser querido, Gloria Mancilla y sus hijas tuvieron que enfrentarse a vivir en carne propia la crudeza del conflicto: desde el momento mismo de la desaparición forzada de Miguel Ángel empezaron las amenazas. Al respecto, Mancilla señala:

Las más comunes eran las llamadas por teléfono en donde generalmente nos decían las vamos a matar a todas. Estas llamadas fueron contestadas indistintamente por mis hijas y la persona que las cuidaba o por mí. Solía ocurrir más en época de vacaciones, especialmente en diciembre. Había mucho seguimiento, durante años, tuve «asignada» a una agente del DAs que me hacía los seguimientos, era tal la situación que ya nos conocíamos y nos encontrábamos en un transporte público, en un supermercado y en eventos políticos ${ }^{33}$.

Durante años Gloria y sus hijas soportaron amenazas de muerte que las obligaban a cambiar constantemente de residencia, hasta que en 2002 se exiliaron en España. Gloria volvió a Colombia en 2003, pero dos años después, luego de que personas extrañas entraran a su casa, revolcaran todo y le dejaran sobre su escritorio un libro escrito por el jefe paramilitar Salvatore Mancuso, volvió al exilio.

Por estos hechos Gloria y sus hijas se encuentran exiliadas en España y desde allí ha continuado su lucha por la verdad y la justicia. Recientemente han elevado una solicitud a la Fiscalía General de la Nación para que este crimen sea considerado de lesa humanidad, y en este sentido evitar su prescripción y su impunidad.

En febrero de 2011, los familiares de Miguel Ángel realizaron un mural en una zona céntrica de la ciudad de Bogotá con el propósito de exaltar su memoria, pero al poco tiempo este mural fue tachado con mensajes que lo calificaban como terrorista (ver imagen 1 ).

Los siguientes son los principales extractos de la entrevista que el autor sostuvo con Gloria Mancilla:

Uno como víctima de la desaparición hace un proceso de etapas, de dificultades que jamás se superan. Creo que una de las cosas terribles de la desaparición es la incertidumbre y la ausencia, la ausencia-presencia, diría yo, porque es una ausencia física, pero una presencia social que se mantiene.

33 Mancilla, entrevistada por el autor.

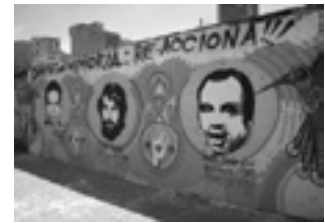

Faustino López, desaparecido (derecha) Miguel Ángel Díaz, desaparecido (centro) Jaime Pardo Leal, asesinado (izquierda).

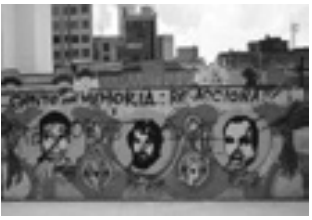

En el mes de febrero de 2011, los familiares de Miguel Ángel realizaron un mural en una zona céntrica de la ciudad de Bogotá con el propósito de exaltar su memoria.

Al poco tiempo este mural fue tachado con mensajes que lo calificaban como terrorista.

Imagen 1.

Fuente: fotos cortesía de la familia Gómez Ramírez. Archivo familiar.

¿Cómo explicarle a un niño de 20 meses una desaparición? ¿Cómo hacerlo con unas niñas de 8 o 10 años como quedaron mis hijas? Eso no fue fácil para mí, y es indudable e impactante los efectos que eso tiene en ellas. [...] Años después de la pérdida de Miguel Ángel mi hija ilustraba ese proceso como un ojo cerrado: hay un ojo cerrado y mediante etapas se empieza a abrir el ojo, y al final, cuando se abre, del ojo caen lágrimas; y la explicación que ella daba era que uno no veía ni conocía el mundo, pero que llega un momento en que empieza uno a mirar y encuentra cosas muy dolorosas y violentas, y es entonces cuando se conoce el mundo, y esa referencia ella la hacía en relación con la pérdida de su papá. [...]

E1 desarraigo es muy doloroso, tener que salir a la fuerza de un sitio. Todo lo que sea a la fuerza no es bueno. Si en Colombia el traslado de la gente es tan doloroso y tan brutal, imagínese de un país a otro. Es muy difícil. Porque, por ejemplo, estando en Colombia en un comienzo usted puede perder el contacto con su familia, pero al final se puede encontrar, es posible encontrarse con su ser querido en alguna ciudad en algún sitio. Pero en el caso nuestro con el exilio, no podemos volver a Colombia.

Vale, yo he tenido acceso a poder salir del país, salvar mi vida, diría que mi vida física porque el resto de cosas que yo construí en vida de un tajo casi que las pierdo. Yo tuve la fortuna que aquí me aceptaron con mis tres hijas, pero hay mucha gente que tiene que salir sola. Y aunque salí con mis tres hijas, quedaron atrás mi mamá, mis hermanos, mis sobrinas, mi familia, es un corte brutal en eso. [...]

El exilio de alguna manera es acabar con la fuerza del líder social. Es volver a nacer, viejo y sin que nadie le enseñe a uno. Es muy difícil: usted pierde su historia, su historia laboral, social, política, y la familiar en alguna medida, digo en alguna medida porque yo estoy con mis hijas. [...]

Desafortunadamente la desaparición es un delito de lesa humanidad que se ha ejecutado por agentes estatales bajo la idea de desaparecer al opositor político. En el caso de Miguel Ángel es clara la desaparición y lo más grave de eso es que uno elige su gobierno, uno va a las elecciones y elige sus representes para que nos protejan, y entonces son estos «protectores» los que 
ejecutan estas barbaries, los que terminan desapareciendo. Ósea que es mucho más grave que si el delito lo ejerciera un particular, sin que deje ser grave. [...]

Si uno mira la historia viene la tortura, viene la masacre, viene la desaparición, vienen todas juntas, viene el asesinato selectivo, y ahora nos están planteando «indemnizaciones» que son una ofensa para las víctimas, y le están diciendo al mundo que ya estamos en un proceso de paz, y yo no entiendo qué elementos hay de paz, con qué cara nos dicen que están haciendo la paz, que estamos en casi un posconflicto en ese país donde hay tanta barbarie y donde no han reparado nada, no han devuelto la tierra, no han devuelto a los campesinos a sus sitios con todos sus derechos. [...]

Es monstruosa la manera como el paramilitarismo fue desarrollado como herramienta de los que detentan poder para no perderlo. $\mathrm{Y}$ ya los mismos jefes paramilitares han dicho que a ellos los creó el Estado, el poder. ¿Cuántos políticos han sido juzgados o investigados? A mí me da dolor de patria ver que casi que el país está tomado por el paramilitarismo. Es impresionante la corrupción y el engaño que le han hecho al país, el saqueo de tierras que le han hecho al campesino, las mejores tierras, las más productivas, que ahora están relacionadas con los mega proyectos productivos y es por eso es que muchas veces las multinacionales aparecen relacionadas con el paramilitarismo, financiando esta empresa de la muerte. [...]

Acá no hay víctimas de primera o de segunda, porque igual dolor es el del campesino que le quitan su familia al que se me produjo a mí. Entonces, yo no sé cómo pueden hablar de casos emblemáticos, es una vergüenza, de verdad, es indignante.

¿Cómo pudieron muy rápidamente matar tanta gente? Con responsabilidad estatal porque es que la hay por acción o por omisión. Entonces que no me vengan a decir que toda la barbarie que hicieron ahora son incapaces de repararla e investigarla. Me parece que es de lo más ofensivo que pueden hacer, de lo más indignante y de lo más antiético. [...]

¿Cuántas personas vinculadas al paramilitarismo están en el Congreso haciendo esas leyes horrorosas? Entonces, ¿qué justicia y que reparación hay en eso? ¿Qué posibilidad de paz hay en eso? ¿Qué construcción de un nuevo país puede haber? Yo, por ejemplo, no acepto que el caso de Miguel Ángel sea calificado de ninguna otra manera. Sencillamente Miguel Ángel era un dirigente sindical del que queremos saber la verdad de qué pasó y que se investigue y se castigue. Ya otra cosa es que alguno que estuvo vinculado a la desaparición de Miguel Ángel estuvo vinculado en cincuenta o en cien casos más, pues que se le juzgue por todos, porque igual derecho tiene cualquiera de las víctimas a la verdad y a la reparación. [...]

En lo que respecta a la reparación la verdad es necesaria, es indispensable. Hay una frase famosa que dice que «quien no conoce su historia está condenado a repetirla», y la verdad tiene que ver con eso, pero también tiene que ver con el tema. No sé, es un tema muy fácil de mencionar en el caso de la desaparición que es la incertidumbre. A pesar de que uno sabe que en la región en donde desaparecieron había una barbarie espantosa uno siempre se pregunta si lo han de- jado torturado por ahí, si está vivo. ¿Quién garantiza algo que uno tiene que «suponer»?, porque ni siquiera las investigaciones han tocado a quienes deberían tocar, como en el caso de Miguel Ángel.

Ese ocultamiento de la verdad lo que hace es mantener ese sistema y acostumbrar a la gente a que esto puede pasar, y es lo que genera para la familia mucho dolor e incertidumbre, pero también para la sociedad, pues las personas que desaparecen también son seres sociales.

Y allí también se debe hablar de reparación. La reparación también debe ser social. Esa reparación el Estado la reduce a unas monedas y esa reparación también tiene que ver con lo social: la verdad de quién es el desaparecido. Muchas veces dice la gente «ah, seguramente era guerrillero», ¿y es que el guerrillero no tiene derecho a que lo juzguen? Si es que era guerrillero. [...] Hay que reparar a la organización social, la organización laboral, la organización política a la que pertenecía, al sindicato, por ejemplo, los daños que ha causado la desaparición en todos esos sectores. Una desaparición causa mucho daño, por eso es tan importante la verdad para empezar a reparar y entender.

Personalmente, hago un llamado a que miremos de otra manera lo que está pasando en el país y a que hagamos un ejercicio ético de intentar cambiar las cosas, y hago un llamado a que desde afuera nos ayuden. Es fundamental que la comunidad internacional nos ayude en el tema de DDHH y de medios de información, así que hago un llamado a generar conciencia del papel de los medios, de buscar medios alternativos de comunicación, y principalmente a la solidaridad, de crear lazos de solidaridad ${ }^{34}$.

La desaparición de Miguel Ángel Díaz fue un crimen no solo contra él y su familia, sino también contra el movimiento sindical colombiano y en general contra quienes defendían la posibilidad de una democracia abierta, participativa y pluralista. En la instalación del xi Congreso de Fenaltrase, Jaime Pardo Leal se referiría en estos términos al crimen de Miguel Ángel:

Desde hoy pasarán tres días para recordar la memoria de Miguel Ángel Díaz. La memoria de nuestros mártires es el aliento constante que nos reta a la acción contra el miedo y el terror. Esta Federación lleva a Miguel Ángel Díaz, como a Dionisio Calderón y a cuantos más. El recuerdo de estos hombres que fueron imprescindibles aún después de que su vida consolidará a la Federación y elevará su capacidad de acción en el país, dentro de la fase de la guerra sucia, de la facistización del país ${ }^{35}$.

Cuarenta días después de pronunciar estas palabras el propio Jaime Pardo Leal sería asesinado.

34 Mancilla, entrevistada por el autor.

35 Ortiz Palacios, Jaime Pardo Leal, 144. 
El 11 de octubre de 1987, en la vía Bogotá-La Mesa, sicarios interceptaron el vehículo en que Jaime Pardo Leal, dirigente de la UP, se movilizaba con su familia y allí fue asesinado ante los ojos de su hijo y su esposa. El asesinato de un carismático líder político, así como el de los miles de militantes que compartían sus ideas, es un hecho que debe no solamente ser repudiado desde todo punto de vista, sino que además debe incentivar acciones que garanticen y que muestren a quienes usan la violencia como herramienta política que las ideas no es posible asesinarlas, que las ideas no mueren con el hombre. Aquellas balas asesinas que silenciaron la vida de Pardo Leal «nos han entregado a las nuevas generaciones el deber de reivindicarlos, de reconstruir el proyecto político que defendió, de recordarlo para demostrarle a los asesinos que la esperanza aún existe y que los hombres morimos pero las ideas realmente valiosas, esas siempre sobreviven ${ }^{36}$.

\section{5 años después: entre el acceso a la justicia de las víctimas y la justicia transicional para la superación del conflicto}

Superado el siglo xx, y luego de casi 25 años del auge del paramilitarismo, del narcotráfico y de la lucha guerrillera, estos actores aún persisten en la realidad colombiana, pero el equilibrio de poder entre ellos ha sido radicalmente modificado.

Luego de la década de los noventa en que fracasó un nuevo proceso de paz con las FARC, y en que estas y los grupos paramilitares (organizados bajo un comando central y denominados Autodefensas Unidas de Colombia [AUC]) se consolidaron militar y geográficamente en el territorio nacional, en 2002 llegó a la presidencia Álvaro Uribe Vélez con su política denominada «Seguridad democrática», que en términos generales planteaba una lucha frontal contra las estructuras guerrilleras, al tiempo que se iniciaba un proceso de paz con los grupos paramilitares. En 2003 las AUC iniciaron un proceso de desmovilización y el gobierno inició el trámite de un marco legislativo de justicia transicional para los desmovilizados:

36 Ortiz Palacios, Jaime Pardo Leal, 154. la Ley 975 de $2005^{37}$ que se conoció como Ley de Justicia y Paz. A 6 años de iniciado el proceso de desmovilización de las Auc y de vigencia de la Ley de Justicia y Paz las cifras del proceso no eran nada alentadoras:

\begin{abstract}
Llama mucho la atención y preocupa que solamente se han emitido cuatro condenas desde su creación, y solamente una está firme [...] se presentan serias fallas en el proceso de reinserción de los paramilitares desmovilizados pues muchas veces no gozan de las garantías y servicios para este proceso por lo que vuelven a delinquir. [...] De los más de 54 mil desmovilizados registrados en estos últimos seis años, cerca de 6.500 han reincidido en actividades criminales, o se han unido a las llamadas bandas criminales. Según el informe presentado por la Procuraduría, más de 2.400 han sido asesinados en medio de extrañas circunstancias que son motivo de investigación, pero se cree que obedecen a venganzas personales ${ }^{38}$.
\end{abstract}

En lo que respecta al narcotráfico, la atomización del negocio ha sido el común denominador. El negocio de la droga ya no es controlado por grandes carteles, sino que existen numerosos pequeños y medianos narcotraficantes, y las FARC lo convirtieron en una de sus principales fuentes de financiación.

Por su parte, el gobierno de Juan Manuel Santos ha iniciado un proceso de paz con el grupo guerrillero de las FARc. En tal proceso se aprobó en el Congreso de la Republica una reforma constitucional denominada Marco Legal para la Paz, que en términos generales plantea un modelo de justicia transicional en el que se priorizarán y seleccionarán, con base en criterios de selección dispuestos por el legislativo, los casos más emblemáticos e importantes para ser judicializados, y sobre los demás casos se implementarán mecanismos no judiciales de investigación y sanción ${ }^{39}$. Siendo el Estado colombiano consiente

\footnotetext{
37 Congreso de Colombia. Ley 975 del 25 de julio de 2005. Por la cual se dictan disposiciones para la reincorporación de miembros de grupos armados organizados al margen de la ley, que contribuyan de manera efectiva a la consecución de la paz nacional y se dictan otras disposiciones para acuerdos humanitarios.

38 «"La ley de Justicia y Paz presenta escasos resultados": Procuraduría», El Espectador [Bogotá], 4 de octubre, 2011. http://www.elespectador.com/noticias/judicial/articulo-303488-ley-de-justicia-ypaz-presenta-escasos-resultados-procuraduria (consultado el 23 de octubre de 2013).

39 Exposición de motivos. Proyecto de Acto Legislativo. Por medio del cual se adiciona un nuevo artículo transitorio 66 a la Constitución Política de Colombia y se modifica el artículo 122 constitucio-
} 
de su incapacidad para investigar y juzgar efectivamente cada uno de los crímenes cometidos dentro del contexto del conflicto colombiano, y atendiendo al desbordamiento de este, en el que diversos actores (paramilitares-narcotráfico-guerrilla) han desangrado durante décadas a Colombia ${ }^{40}$, esta reforma constitucional se convirtió en la primera respuesta del Gobierno para proporcionar un marco jurídico que permita la superación definitiva del conflicto. E1 31 de julio de 2012 el Marco Legal para la Paz se convirtió en norma constitucional. Este modelo de justicia transicional coloca sobre el escenario la incapacidad material del Estado para judicializar cada uno de los delitos perpetrados en el marco del conflicto. Sin embargo, esta declarada incapacidad no puede derivar en la impunidad de estos crímenes. La verdad para todas las víctimas del conflicto es elemento indispensable e innegociable en cualquier proceso de reparación.

A través de experiencias internacionales en materia de justicia transicional y reconciliación, como Chile, Argentina o Uruguay, se ha observado cómo el Estado no llegó nunca a procesar judicialmente cada uno de los casos denunciados. Empero, en estos países la Comisión de la Verdad cumplió un trascendental papel de justicia, verdad y reparación. Las víctimas del conflicto colombiano y el país entero tienen derecho, merecen y necesitan saber la verdad sobre el conflicto y cómo este ha operado en todas las esferas y niveles de la sociedad y el Estado. Sin una Comisión de la Verdad con reales garantías para su funcionamiento resulta ingenuo pensar que toda la verdad se dará a conocer simplemente por boca de los actores del conflicto.

Las víctimas del conflicto vienen reclamando desde hace décadas un real acceso a la justicia. Dada la magnitud del conflicto, si se pretende consolidar un proceso de reconciliación y superación

nal, con el fin de darle coherencia a los diferentes instrumentos jurídicos de justicia transicional en el marco del artículo 22 de la Constitución Política.

40 El reciente informe del Grupo de Memoria Histórica sobre el conflicto armado colombiano denominado iBasta ya! Colombia: memorias de guerra y dignidad revela que entre 1958 y 2012 el conflicto armado ha causado la muerte de 218.094 personas. El informe completo puede consultarse online en http://www.centrodememoriahistorica.gov.co definitiva del conflicto, resultan bienvenidos los mecanismos de justicia transicional que establecen alternativas de acceso a la justicia, pero siempre con estándares de no impunidad, reparación y conocimiento de la verdad.

En este sentido, la jurisprudencia de la Corte Constitucional ha reiterado que son derechos de las víctimas el conocer la verdad sobre lo sucedido, la justicia (que comprende i) el deber del Estado de investigar y sancionar adecuadamente a los autores y partícipes de los delitos; ii) el derecho de las víctimas a un recurso judicial efectivo; iii) el deber de respetar en todos los juicios las reglas del debido proceso), y la reparación integral (que comprende la adopción de medidas individuales relativas al derecho de i) restitución, ii) indemnización, iii) rehabilitación, iv) satisfacción y v) garantía de no repetición) ${ }^{41}$.

Es evidente que la reivindicación natural de una víctima es la de la justicia, en palabras de Gloria Mancilla: «Acá no hay víctimas de primera o de segunda, porque igual dolor es el del campesino que le quitan su familia al que se me produjo a mí. Entonces, yo no sé cómo pueden hablar de casos emblemáticos, es una vergüenza, de verdad, es indignante» ${ }^{42}$. Ahora bien, en medio de procesos de justicia transicional, la justicia no se reduce a la aplicación de una pena privativa de la libertad. Por el contrario, es deseable y necesario la implementación de formas alternativas de penalización, pero siempre como requisito indispensable el conocimiento de la verdad como forma primaria de reparación moral a las víctimas, además de reparaciones económicas y garantías de no repetición.

En escenarios de justicia transicional los derechos de las víctimas pueden aceptar ponderaciones en las cuales un componente se vea atenuado en beneficio de los demás. Así, el derecho a que se investiguen y sancionen las conductas punibles podría ser atenuado si se garantizan los derechos a la verdad y a la reparación integral. En el caso colombiano será el Congreso de la República el encargado de elaborar una ley estatutaria que reglamente las condiciones específicas del modelo

\footnotetext{
41 Corte Constitucional de Colombia, Sentencia de constitucionalidad C-454 del 7 de junio de 2006, Magistrado Ponente: Dr. Jaime Córdoba Triviño.

42 Mancilla, entrevistada por el autor.
} 
de justicia transicional que el país va a adoptar si se logra una finalización negociada del conflicto.

En todo caso, es un paso fundamental hacia la reconciliación un reconocimiento pleno del Estado de la tragedia humanitaria que desde hace 25 años atraviesa la nación y de su parte de responsabilidad en la tragedia. Como se indicó, absolutamente todas las víctimas del conflicto tienen derecho y necesitan ser reparadas, siendo el conocimiento de la verdad el paso indiscutible para ello. Por este motivo, es indispensable que, sea cual sea el modelo de justicia transicional que se adopte, las víctimas sientan que sus derechos son respetados y que, si bien es posible que no todos los responsables materiales de crímenes sean judicializados, todas las víctimas sean resarcidas con la verdad y la reparación integral. Es obligatorio que todas las víctimas sientan que fueron reparadas por el Estado, aun cuando dicha reparación no implique necesariamente la judicialización del responsable.

\section{Bibliografía}

\section{Fuentes primarias}

Mancilla, Gloria. Entrevistada por el autor. Madrid, 21 de enero, 2012.

\section{Fuentes secundarias}

"La ley de Justicia y Paz presenta escasos resultados": Procuraduría». El Espectador [Bogotá], 4 de octubre, 2011. http://www.elespectador.com/noticias/judicial/articulo-303488-ley-de-justiciay-paz-presenta-escasos-resultados-procuraduria «Condena a nación por asesinato de Pardo Leal». El Tiempo [Bogotá], 1 de noviembre, 1997. http://www.eltiempo.com/archivo/documento/ MAM-698810

Ávila Martínez, Ariel Fernando. «Injerencia política de los grupos armados ilegales». En $Y$ refundaron la patria... De cómo mafioso y politico reconfiguraron el Estado Colombiano, editado por Claudia López, 79-90. Bogotá: Debate, 2010.

Barón Porras, Luis Fernando. Historias no oficiales de guerra y paz. Bogotá: cinep, 2006.

Campos Zornosa, Yesid. El baile rojo. Relatos no contados del genocidio de la UP. Bogotá: Debate, 2008.
Centro de Memoria Histórica. ¡Basta ya! Colombia: memorias de guerra y dignidad. http://www. centrodememoriahistorica.gov.co

Comisión Interamericana de Derechos Humanos. Informe $n^{\circ}$ 5/97, caso 11.227, sobre admisibilidad, Colombia, 12 de marzo de 1997. http://www.cidh. org/annualrep/96span/colombia11227.htm

Congreso de la Republica de Colombia. Exposición de motivos. Proyecto de Acto Legislativo. Por medio del cual se adiciona un nuevo artículo transitorio 66 a la Constitución Política de Colombia y se modifica el artículo 122 constitucional, con el fin de darle coherencia a los diferentes instrumentos jurídicos de justicia transicional en el marco del artículo 22 de la Constitución Política.

Congreso de la Republica de Colombia. Ley 975 del 25 de julio de 2005. Por la cual se dictan disposiciones para la reincorporación de miembros de grupos armados organizados al margen de la ley, que contribuyan de manera efectiva a la consecución de la paz nacional y se dictan otras disposiciones para acuerdos humanitarios.

Corte Constitucional de Colombia. Sentencia C-454 del 7 de junio de 2006. Magistrado Ponente: Dr. Jaime Córdoba Triviño.

Corte Interamericana de Derechos Humanos. Caso Manuel Cepeda Vargas Vs. Colombia. Excepciones Preliminares, Fondo, Reparaciones y Costas. Sentencia de 26 de mayo de 2010. Serie C No. 213. http://www.corteidh.or.cr/docs/casos/articulos/ seriec_213_esp.pdf

García Villegas, Mauricio; Javier Revelo Rebolledo y Rodrigo Uprimny Yepes. «Impacto constitucional e institucional de la Ley de Justicia y Paz». En Y refundaron la patria... De cómo mafiosos y politicos reconfiguraron el Estado Colombiano, editado por Claudia López, 317-331. Bogotá: Debate, 2010.

Herrera Durán, Natalia. «La lucha de la familia Díaz Mancilla». El Espectador [Bogotá], 5 de septiembre, 2011. http://www.elespectador.com/ noticias/judicial/lucha-de- familia-diaz-manci1la-articulo-297185

López Hernández, Claudia. «La refundación de la Patria, de la teoría a la evidencia». En $Y$ refundaron la patria... De cómo mafiosos y políticos reconfiguraron el Estado Colombiano, editado por Claudia López, 29-78. Bogotá: Debate, 2010. 
Lozano Guillen, Carlos A. «Familiares en pie de lucha». Semanario Voz [Bogotá], 14 de septiembre, 2011, 3.

Ortiz Palacios, Iván David. Genocidio politico contra la Unión Patriótica: nuevas miradas para nuevas lecturas. Bogotá: Universidad Nacional de Colombia, 2006.

Ortiz Palacios, Iván David. Jaime Pardo Leal, Patriota de la Unidad. Bogotá: Universidad Nacional de Colombia, 2008.

Otero Prada, Diego. Las cifras del conflicto colombiano. Bucaramanga: Uniciencia, 2007.

Patiño Villa, Carlos Alberto. Guerra y construcción del Estado en Colombia 1810-2010. Bogotá: Universidad Militar Nueva Granada, 2010.

Pecaut, Daniel. Crónica de cuatro décadas de política colombiana. Bogotá: Grupo Editorial Norma, 2006.

Pecaut, Daniel. Guerra contra la sociedad. Bogotá: Espasa, 2001.

Peñaranda, Ricardo. «La guerra en el papel. Balance de la producción sobre la violencia durante los años noventa». En Pasado y presente de la violencia en Colombia, compilado por Gonzalo Sánchez y Ricardo Peñaranda, 33-46. Medellín: La Carreta Editores, Medellín, 2007.

Presidencia de la República de Colombia. Decreto 1357 del 10 de junio de 1964. Por el cual se dictan disposiciones sobre el levantamiento de los censos nacionales de Población, Edificios, Viviendas y Ganadero.

Presidencia de la República de Colombia. Decreto 1705 del 11 de agosto de 1960. Por el cual se reorganiza el Ministerio de Guerra y se determinan sus funciones.

Presidencia de la República de Colombia. Decreto 3398 del 25 de enero de 1965. Por el cual se organiza la defensa nacional.
Redacción Judicial. «Revive el caso de Bernardo Jaramillo». El Espectador [Bogotá], 21 de noviembre, 2009. http://www.elespectador.com/ impreso/judicial/articuloimpreso173433-revive-el-caso-de-bernardo-jaramillo

Sánchez, Gonzalo. «Los estudios sobre la violencia: balance y perspectivas». En Pasado y presente la violencia en Colombia, compilado por Gonzalo Sánchez y Ricardo Peñaranda, 17-32. Medellín: La Carreta Editores, 2007.

Secretaría de la Declaración de Ginebra sobre Violencia Armada y Desarrollo. Carga Global de la Violencia Armada 2011. Encuentros letales. http:// www.genevadeclaration.org/measurability/global-burden-of-armed-violence/global-burdenof-armed-violence-2011.html

Turbay Jiménez, Catalina. «E1 Estatuto de Seguridad: un estudio de caso». En 1er. Congreso de ciencia politica, 30 de septiembre al 4 de octubre de 2008. http://congresocienciapolitica.uniandes.edu.co/

Fecha de recepción: 21 de agosto de 2014

Fecha aprobación: 14 de octubre de 2014

Disponible en línea: 8 de abril de 2014

\section{Cómo citar este artículo}

Tobar Torres, Jenner Alonso. «Violencia política y guerra sucia en Colombia. Memoria de una víctima del conflicto colombiano a propósito de las negociaciones de la Habana». Memoria y Sociedad 19, no. 38 (2015): 11-24. http://dx.doi.org/10.11144/ Javeriana.mys19-38.vpgs 